\title{
Long-term effects of antihypertensive medications on bone mineral density in men older than 55 years
}

This article was published in the following Dove Press journal:

Clinical Interventions in Aging

27 March 2014

Number of times this article has been viewed

\author{
Kamil Serkan Ağaçayak' \\ Sedat Güven² \\ Mahmut Koparal' \\ Nedim Güneș' \\ Yusuf Atalay ${ }^{3}$ \\ Serhat Atılgan' \\ 'Department of Oral and \\ Maxillofacial Surgery, ${ }^{2}$ Department \\ of Prosthodontics, School of \\ Dentistry, University of Dicle, \\ Diyarbakır, Turkey; ${ }^{3}$ Department \\ of Oral and Maxillofacial Surgery, \\ School of Dentistry, University of \\ Afyon Kocatepe, Afyon, Turkey
}

Introduction: In this study, we investigated the effects of long-term antihypertensive treatment with calcium channel blockers or beta blockers on the bone mineral density of maxilla, as determined by cone-beam computed tomography (CBCT).

Material and methods: This retrospective study was conducted on CBCT images of men older than 55 years who had received different dental indications. Data were grouped into three categories according to the antihypertensive medication history of the patients: group A included patients who had been taking beta-blocker treatment for more than 5 years, group B included patients who had been taking calcium channel blocker treatment for more than 5 years, and the control group included patients who had never used any hypertensive medications before.

Results: Statistically significant differences were observed between the beta blocker and calcium channel blocker groups.

Conclusion: In hypertension treatment, beta blockers may be preferred to calcium channel blockers in patients at high risk for osteoporosis and bone resorption.

Keywords: bone mineral density, CBCT, beta blockers, calcium channel blockers

\section{Introduction}

Osteoporosis is a metabolic bone disorder defined as "a skeletal disease, characterized by low bone mass and microarchitectural deterioration of bone tissue, with a consequent increase in bone fragility and susceptibility to fracture." In the elderly, with decreasing levels of estrogen and testosterone, bone resorption exceeds bone formation; thus, the risk of osteoporosis increases. It has been determined that every third postmenopausal woman and every fifth man older than 50 years suffers from osteoporosis. ${ }^{2}$ In contrast, about two-thirds of the adult population older than 60 years of age are diagnosed with hypertension, and more than half of all older adults receive antihypertensive medication. ${ }^{3}$ Osteoporosis and hypertension, two very common diseases among adults, have been associated with a low dairy intake, which could act as a possible pathogenic link between these two diseases. ${ }^{4}$

At this time, there are many classes of antihypertensive medication, and their effects on bone metabolism have been extensively studied before. In the clinical aspect, beta blockers have also been shown to improve bone mineral density (BMD) in some studies. ${ }^{5,6}$ Nevertheless, Solomon et al did not determine any difference in fracture risk between users and nonusers of beta blockers. ${ }^{7}$ In contrast, the effects of calcium channel blockers, another very widely used group of antihypertensive medications, on BMD are controversial. Zacharieva et al found that 8 weeks of amlodipine treatment was not associated with a marked influence on bone metabolism. ${ }^{8}$ However,
Correspondence: Kamil Serkan Ağaçayak Dicle University Dentistry Faculty, Department of Oral and Maxillofacial Surgery, Diyarbakır, 2I 280 Turkey $\mathrm{Tel}+904122488101$

Fax +904122488001

Email serkanagacayak@gmail.com 
hypertension is a chronic disease, and these medications are generally used throughout the life span. In that sense, 8 weeks of treatment may be too short a time to determine the effects of these medications. Rejnmark et al reported that the risk of hip fractures was reduced significantly (by 6\%) in calcium channel blocker users. They also reported that nondihydropyridine drugs were associated with a larger risk reduction compared with dihydropyridine drugs. ${ }^{9}$ Nonetheless, in a recent study, Takaoka et al argue that calcium channel blocker treatment increases both vertebral and nonvertebral fracture risks in patients. ${ }^{10}$ Cone-beam computed tomography (CBCT) is a gradually prevalent technology that can generate highresolution three-dimensional images of the head-and-neck region with a short scan time and with greatly reduced radiation exposure compared with conventional CT. CBCT has been reported to provide identical information to multislice CT, with a considerable dose reduction. ${ }^{11}$ The advantages of CBCT include a lower exposure dose, low cost, fast scanning time, and lower number of image artifacts compared with CT. CBCT has been used in BMD measurement in many recent studies. ${ }^{12,13}$ In a study by Marquezan et al, a positive correlation was established between the BMD of total bone block measured by dual-energy X-ray absorptiometry and the one measured by CBCT. ${ }^{14}$

In CT imaging, Hounsfield units (HU), which are the standardized numbers, are used to represent the relative density of body tissues according to a calibrated gray-level scale, based on values for air $(-1,000 \mathrm{HU})$, water (0 HU), and bone density $(+1,000 \mathrm{HU})$. HU have been assessed in the jaw region in many studies and have been reported to be a useful method of analyzing bone density. ${ }^{15}$

In this study, we aimed to investigate the differences between the effects of long-term antihypertensive treatment with calcium channel blockers and beta blockers on the BMD of maxilla by using CBCT.

\section{Materials and methods}

This study was conducted at the Faculty of Dentistry, Department of Oral and Maxillofacial Surgery, Dicle University, Diyarbakır, Turkey. The ethics committee at Dicle University Faculty of Medicine approved the study (Protocol no 122). The retrospective study was conducted on CBCT images of male patients older than 55 years who had received different dental indications. In addition, it was a retrospective way to determine the control group.

Cone-beam dental volumetric tomography (I-Cat; Imaging Sciences International, Hatfield, PA, USA) was used to take images of the maxilla-facial area at a setting of $120 \mathrm{kVp}$ and $3.7 \mathrm{~m} \AA$. Images were obtained within 10 seconds (the actual exposure time was 9 seconds). Each scan involved a number of separate, small, individual exposures (up to 440 frames) taken over $360^{\circ}$ with a voxel size of $0.300 \mathrm{~mm}$.

The tomography data were grouped into three categories depending on the antihypertensive medication history of the patients. Group A consisted of the patients who had been receiving beta-blocker treatment for more than 5 years, group B comprised the patients who had been receiving calcium channel blocker treatment for more than 5 years, and the control group included the patients who had never used any hypertensive medications before. The patients who had a history of any cancers, diabetes mellitus, Paget's disease, thyroid dysfunctions, or osteoporosis or who had received radiotherapy, chemotherapy, or any treatment for osteoporosis before were excluded from the study. Moreover, the patients with a severe pathology in their jaw region including defects, tumor, or cyst were also excluded from the study. The patients with severe maxilla resorption and the ones with insufficient distance for measurement between the sinus region and teeth roots were not included in the study.

\section{CBCT procedure}

A total of 294 dental tomography scans of male patients older than 55 years, all of whom had been performed for different indications, were evaluated. The $\mathrm{CBCT}$ scans were obtained and reviewed by the same radiologist with the I-Cat Vision program. The procedure began when all the scans were taken as preview screen images (Figure 1A and B), a $1.8 \mathrm{~mm}^{2}$ area was selected approximately $1 \mathrm{~mm}$ away from the apexes of teeth, and the molar, premolar, canine, incisor teeth, and tuber regions of maxilla (Figure 1A and B) and HU-statistic values were obtained from five different regions of the selected area. The exact HU-statistic measurements were obtained from the apexes of incisors (central and lateral), the apex of canine tooth, the apex of premolars, the apex of molars, and the region of tuber maxilla. Moreover, mean maxilla values were also determined via the means of these five determinants. The measurements of patients with partial loss of teeth were also achieved from the same regions.

\section{Statistical analysis}

The statistical analyses were performed using SPSS Statistics 18.0 software (IBM Corporation, Armonk, NY, USA). For the comparison variables, it was used post hoc, as they were homogeneous and the distribution was normal. Statistical significance level was accepted at $P<0.05$. 

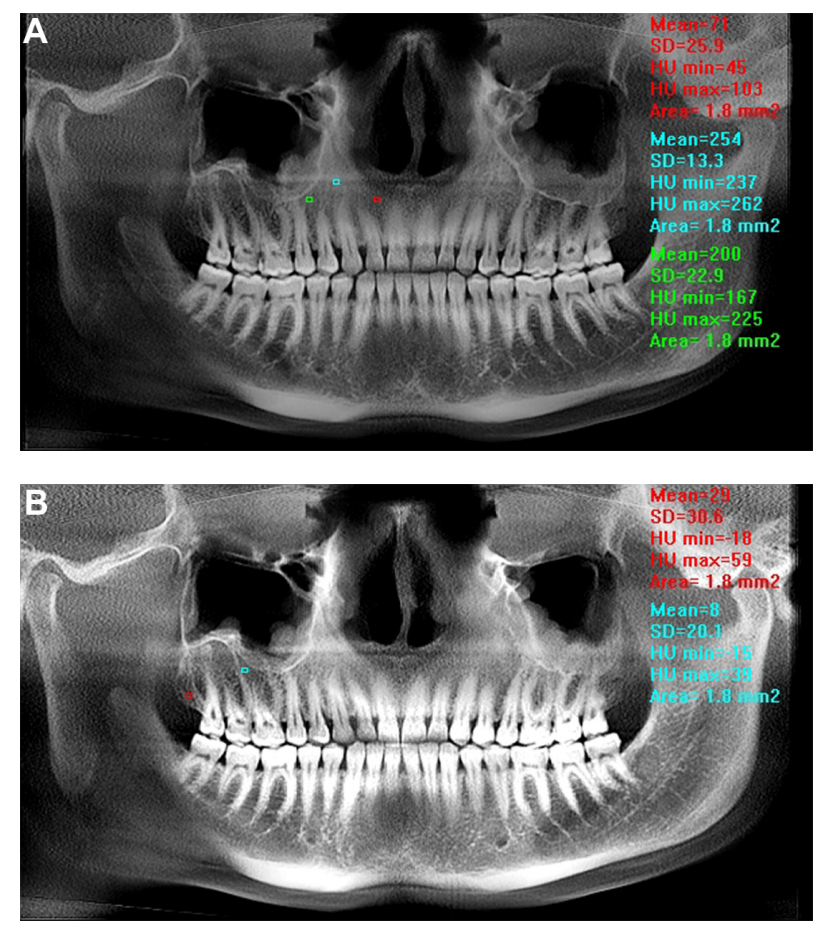

Figure I The exact Hounsfield unit statistic measurements were obtained from the apexes of incisors (central and lateral), the apex of canine tooth, the apex of premolars, the apex of molars, and the region of tuber maxilla. These regions of measurements are shown on the figure as $1.8 \mathrm{~mm}^{2}$ colorful square points.

Abbreviations: $\mathrm{HU}$, Hounsfield units; SD, standard deviation.

\section{Results}

The subjects included men older than 55 years; they had a mean age of 58 years. The radiographic characteristics of all participants are summarized in Table 1 . The incisor region of maxilla $(P=0.034)$, premolar region of maxilla $(P=0.013)$, and mean value of maxilla $(P=0.008)$ presented significant differences in the beta blocker and calcium channel blocker groups. The values of the beta blocker group were better than the values of the calcium channel blocker group. The values of the calcium channel blocker group were worse than the control group in all measured areas, and there was no statistically significant difference in any region between the control and study groups.

\section{Discussion}

In this study, by using CBCT, we determined significantly better BMD values on maxilla among the patients who had been receiving beta blocker treatment for at least 5 years compared with the patients who had been receiving calcium channel blockers for at least 5 years. Because osteoporosis is a very important health problem in the elderly, especially because of the increased fracture risk, the difference between these two widely used drug groups is of major importance.
Table I Bone mineral density values obtained by cone-beam computerized tomography

\begin{tabular}{|c|c|c|c|}
\hline Regions & $\begin{array}{l}\text { Variables } \\
\text { Control group }(n=\mid 48) \\
\text { Beta-blocker group }(n=67) \\
\text { Ca-channel blocker group }(n=79)\end{array}$ & $\begin{array}{l}\text { Mean } \\
\text { difference }\end{array}$ & Sig \\
\hline \multirow[t]{5}{*}{ Incisor } & Beta-blocker group & & \\
\hline & Control group & 37.01896 & 0.188 \\
\hline & Ca-channel blocker group & 59.67240 & 0.034 \\
\hline & Ca-channel blocker group & & \\
\hline & Control group & -22.65344 & 0.495 \\
\hline \multirow[t]{5}{*}{ Canine } & Beta-blocker group & & \\
\hline & Control group & $|2.7276|$ & 0.767 \\
\hline & Ca-channel blocker group & 19.04723 & 0.627 \\
\hline & Ca-channel blocker group & & \\
\hline & Control group & -6.31962 & 0.929 \\
\hline \multirow[t]{5}{*}{ Premolar } & Beta-blocker group & & \\
\hline & Control group & 27.38594 & 0.265 \\
\hline & Ca-channel blocker group & $56.48592^{*}$ & 0.013 \\
\hline & Ca-channel blocker group & & \\
\hline & Control group & -29.09998 & 0.188 \\
\hline \multirow[t]{5}{*}{ Molar } & Beta-blocker group & & \\
\hline & Control group & -16.30456 & 0.569 \\
\hline & Ca-channel blocker group & 40.20877 & 0.070 \\
\hline & Ca-channel blocker group & & \\
\hline & Control group & 23.90421 & 0.260 \\
\hline Tuberositas & Beta-blocker group & & \\
\hline \multirow[t]{4}{*}{ maxilla } & Control group & 0.23054 & 1.000 \\
\hline & Ca-channel blocker group & 10.39732 & 0.496 \\
\hline & Ca-channel blocker group & & \\
\hline & Control group & -10.16678 & 0.386 \\
\hline Mean value & Beta-blocker group & & \\
\hline \multirow[t]{4}{*}{ of maxilla } & Control group & 18.73352 & 0.206 \\
\hline & Ca-channel blocker group & $37.16233^{*}$ & 0.008 \\
\hline & Ca-channel blocker group & & \\
\hline & Control group & $-|8.4288|$ & 0.182 \\
\hline
\end{tabular}

Note: Bold face indicates statistical significance.

Abbreviations: Sig, significance; CA, calcium.

Moreover, osteoporosis and hypertension coexist in many patients, and the use of antihypertensive drugs could influence the potential effects of these diseases on the bones.

The effects of beta blockers on BMD have been formerly investigated in several studies. Inactivation of the sympathetic nervous system impairs osteoclastic bone resorption, and thus increases bone formation in animal models. ${ }^{16}$ The data from human studies about the effects of beta blockers on osteoporosis is almost the same. Although in some studies improvements on BMD with beta blocker treatment have been proven, ${ }^{17}$ in other studies no effects of these drugs on bone metabolism have been reported. ${ }^{18,19}$ Similarly, the effects of beta blockers on fracture risk have also been studied, and they were found to decrease fracture risk in some studies ${ }^{9,17}$ and to be ineffective in others..$^{20,21}$ In a recent study, mice 
were intraperitoneally treated 3 days after ovariectomy, using nifedipine, telmisartan, enalapril, propranolol, or hydrochlorothiazide for 35 consecutive days. The study revealed that the use of enalapril and propranolol compared with the control group led to increased BMD loss in mice with atrophied uteri and that only thiazide and telmisartan reduced bone loss and bone fraction in mice with uterine atrophy compared with in the control group. ${ }^{22}$

Osteoporosis is the most common metabolic bone disorder. It is an important public health problem not only because of its high prevalence but also because of its main complication: increased fracture risk. Osteoporotic fracture forces a considerable health burden as a result of reduced mobility, increased requirements for hospitalization, and increased risk for mortality. ${ }^{23}$ Hypertension and osteoporosis coexist in many patients, and this coexistence has been attributed not only to the high prevalence of both diseases but also to some environmental, genetic, and dietary factors. ${ }^{24}$ Although the data in the literature about the association of hypertension with osteoporosis are controversial, recently, hypertension has been associated with increased fracture risk in patients, independent of BMD, in a study. ${ }^{25}$ In this respect, antihypertensive treatment gains more importance, and the effects of these drugs on bone metabolism should be evaluated.

Kapitan-Malinowska et al report that calcium channel blocker treatment increases serum calcium and inorganic phosphate concentrations but has no effect on bone turnover markers or BMD. ${ }^{26}$ In a study investigating whether amlodipine interferes with healing of rat alveolar bone, a $20-30 \%$ decrease in bone volume fraction in the alveolus of amlodipine-treated animals was reported, which may be a sign of decreased osteoblastic activity. ${ }^{27}$ Takaoka et al maintained that calcium channel blocker treatment significantly increases fracture risks after adjustments for age, body mass index, serum creatinine, and blood pressure levels in patients with type 2 diabetes mellitus. ${ }^{10}$ However, these significances disappeared after an additional adjustment for a history of falls. Accordingly, it can be concluded that calcium channel blocker treatment increases fracture risks, possibly via falls.

In our study, the patients receiving calcium channel blocker treatment provided worse values in BMD than the control group did. However, the difference was not statistically significant. When compared with beta blocker-treated patients, beta blocker treatment has significantly positive effects on bone metabolism compared with calcium channel blockers.

CBCT is a new technique with lower radiation dosages, lower costs, and faster scanning in dental imaging. In many studies, it has been used in the determination of bony structures, especially in presurgical imaging for dental implant treatment and the measurement of bone density. ${ }^{28,29}$ Yet there is still no standardized method or standardized values for the evaluation of osteoporosis with CBCT. Further studies are warranted to specify standardized values. If a standardization was established, patients who had to have a CBCT with dental indications might not need to have an extra dual-energy X-ray absorptiometry measurement for the evaluation of osteoporosis, and in this way, one CBCT may serve two purposes.

To the best of our knowledge, this is the first study in literature comparing the effects of these two groups of drugs on the bone metabolism of the jaw region with CBCT.

There are several limitations to this study. First, the blood pressures of participants were regarded as normal and stable under drug treatment. Because hypertension itself may also affect bone metabolism, the changes in blood pressures of participants may also affect our results. In contrast, drug exposure data are based on self-report of patients, though it is not the most reliable method in such research.

\section{Conclusion}

It was revealed that the BMD values on the jaw region with CBCT among patients receiving beta blocker treatment for more than 5 years provide better results compared with those seen for the patients treated with calcium channel blockers. Because hypertension and osteoporosis are two very common diseases and their coexistence is also very common, the results investigating the effects of different treatment groups gain more importance. With these results, it can be concluded that in hypertension treatment, beta blockers may be preferred to calcium channel blockers for patients at high risk for osteoporosis.

\section{Acknowledgments}

The authors are grateful to the Department of Oral and Maxillofacial Surgery, University of Dicle, Diyarbakır, Turkey, for their valuable support.

\section{Disclosure}

The authors report no conflicts of interest in this work.

\section{References}

1. Prevention and management of osteoporosis. World Health Organ Tech Rep Ser. 2003;921:1-164.

2. Olszynski WP, Shawn Davison K, Adachi JD, et al. Osteoporosis in men: epidemiology, diagnosis, prevention, and treatment. Clin Ther. 2004;26(1):15-28.

3. Ong KL, Cheung BM, Man YB, Lau CP, Lam KS. Prevalence, awareness, treatment, and control of hypertension among United States adults 1999-2004. Hypertension. 2007;49(1):69-75. 
4. Varenna M, Manara M, Galli L, Binelli L, Zucchi F, Sinigaglia L. The association between osteoporosis and hypertension: the role of a low dairy intake. Calcif Tissue Int. 2013;93(1):86-92.

5. Pasco JA, Henry MJ, Sanders KM, Kotowicz MA, Seeman E, Nicholson GC; Geelong Osteoporosis Study. Beta-adrenergic blockers reduce the risk of fracture partly by increasing bone mineral density: Geelong Osteoporosis Study. J Bone Miner Res. 2004;19(1):19-24.

6. Schlienger RG, Kraenzlin ME, Jick SS, Meier CR. Use of beta-blockers and risk of fractures. JAMA. 2004;292(11):1326-1332.

7. Solomon DH, Mogun H, Garneau K, Fischer MA. Risk of fractures in older adults using antihypertensive medications. J Bone Miner Res. 2011;26(7):1561-1567.

8. Zacharieva S, Shigarminova R, Nachev E, et al. Effect of amlodipine and hormone replacement therapy on blood pressure and bone markers in menopause. Methods Find Exp Clin Pharmacol. 2003;25(3): 209-213.

9. Rejnmark L, Vestergaard P, Mosekilde L. Treatment with beta-blockers, ACE inhibitors, and calcium-channel blockers is associated with a reduced fracture risk: a nationwide case-control study. J Hypertens. 2006;24(3):581-589.

10. Takaoka S, Yamaguchi T, Tanaka K, et al. Fracture risk is increased by the complication of hypertension and treatment with calcium channel blockers in postmenopausal women with type 2 diabetes. $J$ Bone Miner Metab. 2013;31(1):102-107.

11. Carrafiello G, Dizonno M, Colli V, et al. Comparative study of jaws with multislice computed tomography and cone-beam computed tomography. Radiol Med. 2010;115(4):600-611.

12. González-Martín O, Lee EA, Veltri M. CBCT fractal dimension changes at the apex of immediate implants placed using undersized drilling. Clin Oral Implants Res. 2012;23(8):954-957.

13. Hohlweg-Majert B, Pautke C, Deppe H, Metzger MC, Wagner K, Schulze D. Qualitative and quantitative evaluation of bony structures based on DICOM dataset. J Oral Maxillofac Surg. 2011;69(11): 2763-2770.

14. Marquezan M, Osório A, Sant'Anna E, Souza MM, Maia L. Does bone mineral density influence the primary stability of dental implants? A systematic review. Clin Oral Implants Res. 2012;23(7):767-774.

15. Kaya S, Yavuz I, Uysal I, Akkus Z. Measuring bone density in healing periapical lesions by using cone beam computed tomography: a clinical investigation. J Endod. 2012;38(1):28-31.

16. Bliuc D, Nguyen ND, Milch VE, Nguyen TV, Eisman JA, Center JR. Mortality risk associated with low-trauma osteoporotic fracture and subsequent fracture in men and women. JAMA. 2009;301(5):513-521.

17. Ilić K, Obradović N, Vujasinović-Stupar N. The relationship among hypertension, antihypertensive medications, and osteoporosis: a narrative review. Calcif Tissue Int. 2013;92(3):217-227.
18. Yang S, Nguyen ND, Center JR, Eisman JA, Nguyen TV. Association between hypertension and fragility fracture: a longitudinal study. Osteoporos Int. 2014;25(1):97-103.

19. Cherruau M, Facchinetti P, Baroukh B, Saffar JL. Chemical sympathectomy impairs bone resorption in rats: a role for the sympathetic system on bone metabolism. Bone. 1999;25(5):545-551.

20. Bonnet N, Gadois C, McCloskey E, et al. Protective effect of beta blockers in postmenopausal women: influence on fractures, bone density, micro and macroarchitecture. Bone. 2007;40(5):1209-1216.

21. Pérez-Castrillón JL, Martín-Escudero JC, Alvarez Manzanares P, et al. Hypertension as a risk factor for hip fracture. Am J Hypertens. 2005;18(1):146-147.

22. Reid IR, Lucas J, Wattie D, et al. Effects of a beta-blocker on bone turnover in normal postmenopausal women: a randomized controlled trial. J Clin Endocrinol Metab. 2005;90(9):5212-5216.

23. de Vries F, Pouwels S, Bracke M, et al. Use of beta-2 agonists and risk of hip/femur fracture: a population-based case-control study. Pharmacoepidemiol Drug Saf. 2007;16(6):612-619.

24. Levasseur R, Dargent-Molina P, Sabatier JP, Marcelli C, Bréart G. Beta-blocker use, bone mineral density, and fracture risk in older women: results from the Epidemiologie de l'Osteoporose prospective study. J Am Geriatr Soc. 2005;53(3):550-552.

25. Kang KY, Kang Y, Kim M, et al. The effects of antihypertensive drugs on bone mineral density in ovariectomized mice. J Korean Med Sci. 2013;28(8):1139-1144.

26. Kapitan-Malinowska B, Tałalaj M, Marcinowska-Suchowierska E, Borowicz J, Puchalska-Krotki $\mathrm{H}$. The influence of calcium channel blockers on Ca-P-Mg homeostasis and bone mass in patients with coronary heart disease and hypertension. Osteoporos Int. 1996;6: 184-188. Available from: http://link.springer.com/article/10.1007\%2FBF02500272.

27. Teófilo JM, Brentegani LG, Carvalho TL. A histometric study in rats of the effect of the calcium antagonist amlodipine on bone healing after tooth extraction. Arch Oral Biol. 2001;46(4):375-379.

28. Naitoh M, Aimiya H, Hirukawa A, Ariji E. Morphometric analysis of mandibular trabecular bone using cone beam computed tomography: an in vitro study. Int J Oral Maxillofac Implants. 2010;25(6): 1093-1098.

29. Fuster-Torres MÁ, Peñarrocha-Diago M, Peñarrocha-Oltra D, Peñarrocha-Diago M. Relationships between bone density values from cone beam computed tomography, maximum insertion torque, and resonance frequency analysis at implant placement: a pilot study. Int $J$ Oral Maxillofac Implants. 2011;26(5):1051-1056.
Clinical Interventions in Aging

\section{Publish your work in this journal}

Clinical Interventions in Aging is an international, peer-reviewed journal focusing on evidence-based reports on the value or lack thereof of treatments intended to prevent or delay the onset of maladaptive correlates of aging in human beings. This journal is indexed on PubMed Central, MedLine, the American Chemical Society's 'Chemical Abstracts Ser-

\section{Dovepress}

vice' (CAS), Scopus and the Elsevier Bibliographic databases. The manuscript management system is completely online and includes a very quick and fair peer-review system, which is all easy to use. Visit http://www.dovepress.com/testimonials.php to read real quotes from published authors. 